\title{
Changes in chronotype and social jetlag during adolescence and their association with concurrent changes in BMI-SDS and body composition, in the DONALD Study
}

\author{
Nicole Jankovic $\mathbb{D}^{1 凶}$, Sarah Schmitting $\mathbb{D}^{1,2}$, Bettina Krüger $\mathbb{D}^{3}$, Ute Nöthlings ${ }^{1}$, Anette Buyken (iD ${ }^{3}$ and Ute Alexy (iD ${ }^{1}$
}

(c) The Author(s) 2021

BACKGROUND/OBJECTIVES: Adolescence is a critical period for both the development of overweight and the transition toward a later chronotype, often accompanied by an increase in social jetlag. This study assessed whether changes in chronotype and social jetlag, are linked to changes in body composition during adolescence.

SUBJECTS/METHODS: We used data from the DONALD open cohort study, collected between 2014 and 2019 , from 213 adolescents (9-17 years at baseline, 45\% females) having at least two measures of chronotype and anthropometry $(N=572)$. Chronotype was assessed with the Munich Chronotype Questionnaire and defined as: midpoint of sleep corrected for sleep-debt (MSFsc) accumulated over the week (later MSFsc represents later chronotype). Social jetlag (SJL) defines the difference between midpoint of sleep during week and weekend. Calculations for Fat Free Mass Index (FFMI $\left.\left[\mathrm{kg} / \mathrm{m}^{2}\right)\right]$ ) and Fat Mass Index (FMI) $\left.\left[\mathrm{kg} / \mathrm{m}^{2}\right)\right]$ ) were based on body fat percentage, weight, and height. To analyze the associations, we used linear mixed-effect regression models. Finally, the total cohort was split into three biologically relevant age groups (cut-off set at $<12$ years, $\geq 12$ to $\leq 15$ years and $>15$ years).

RESULTS: Median follow-up was 2.1 years. Overall, change toward a later chronotype was significantly related with an increase in FMI (B: $0.05,95 \% \mathrm{Cl}: 0.01-0.08)$. A $1 \mathrm{~h}$ increase in social jetlag predicted an increase in BMI-SDS of 0.08 SDS units (95\% Cl: $0.01-0.14$ ) and in $\mathrm{FMI}$ of $0.04 \mathrm{~kg} / \mathrm{m} 2$ (95\% Cl: $0.003-0.08)$. Associations were stronger for the age group $\geq 12$ to $\leq 15$ years ( $p$ for interaction: $<0.001)$. No relationship was found with FFMI.

CONCLUSIONS: Changes in MSFsc and SJL during adolescence were associated with concurrent changes in BMI-SDS and FMI. The age $\geq 12$ to $\leq 15$ years appears to be a sensitive period in which chronobiological changes were clearly associated with increasing body fatness.

European Journal of Clinical Nutrition (2022) 76:765-771; https://doi.org/10.1038/s41430-021-01024-y

\section{INTRODUCTION}

Chronotype describes the individual preference in sleep and wake timing [1]. Misalignment between the individual chronotype and socially determined sleep-wake-schedules result in "social jet lag", meaning sleep deficits accumulate during the week and result in oversleep during the weekend [2]. Age and sex are important determinants regarding the individual chronotype [3]. During adolescence (age 9-18 years) a shift from an earlier to a later chronotype occurs [1]. More specifically the age of 12 years has been identified previously in a German population [4] to mark the start in eveningness, whereas the age of about 16 years represented the peak in lateness [5]. These cut-offs may slightly differ between populations [6]. Having a late chronotype and/or being socially jetlagged during adolescence are two important chronobiological factors, associated with a higher BMI [7-9]. In addition, adolescence is considered a critical period for the development of obesity and unfavorable changes of other body composition measures e.g., Fat Mass Index (FMI), likely tracking into adulthood [10, 11].

Hence, our hypothesis was that changes toward later chronotype or an increased social jetlag (SJL) during adolescence are associated with concurrent detrimental changes in body composition that might differ across age groups. We used repeated measurements of the DONALD Study over a median time span of 2.1 years (Q1-Q3:1.9-3.3) to define change in chronotype or SJL and body compositional changes of BMI-SDS, FMI and FFMI.

\section{MATERIALS AND METHODS}

\section{Study design}

The DONALD study is an ongoing, prospectively designed open cohort study conducted in Dortmund, Germany. Since 1985, data on diet, growth,

\footnotetext{
${ }^{1}$ Nutritional Epidemiology, DONALD Study, Department of Nutrition and Food Sciences, Rheinische Friedrich-Wilhelms-University Bonn, Bonn, Germany. ${ }^{2}$ Institute of General Practice and Family Medicine, Faculty of Medicine, Ruhr-University Bochum, Bochum, Germany. ${ }^{3}$ Faculty of Natural Sciences, Institute of Nutrition, Consumption and Health, Paderborn University, Paderborn, Germany. ${ }^{\bowtie}$ email: Nicole.Jankovic@uni-bonn.de
}

Received: 12 October 2020 Revised: 3 September 2021 Accepted: 1 October 2021

Published online: 26 October 2021 
developmental and metabolic factors are continuously collected from infancy (age 3 months) to adulthood. Approximately 30-35 healthy infants from Dortmund and surrounding communities, whose mothers and/or fathers have a sufficient level of the German language, are recruited every year either via personal contacts, maternity wards, or pediatric practices. The examination schedule includes quarterly examinations in infancy, halfyearly examinations in the 2nd year of life and annual examinations thereafter until young adulthood. Examinations include anthropometric measurements, lifestyle questionnaires and a 3-day food record. Chronotype and SJL assessment in the DONALD study started in 2014 for participants from 9 years onwards by use of the Munich Chronotype Questionnaire (MCTQ) $[1,12]$. Detailed information regarding the study design can be found elsewhere [13]. Participants themselves or their parents gave written informed consent. The Ethics Committee of the University Bonn, Germany approved the study.

\section{Study sample}

Among the participants of the DONALD study, those adolescents (aged 9-18 years) with at least two completed MCTQs and parallel collected anthropometric measurements were selected. From 2014 until July 2019, hence considering 5 years of follow-up, $n=620$ study participants completed the MCTQ several times during the study $(N=1163)$. Those questionnaires collected during the 2 weeks after the time change in Germany from standard to summer time or vice versa [14] were excluded $(N=89)$. 378 questionnaires were completed during adulthood (i.e., 18 years and above) leaving $696(n=311)$ completed questionnaires during adolescence. Two participants with incomplete questionnaires $(N=3)$ were also excluded from the dataset. Anthropometric measurements within 1 year before or after completing the MCTQ were missing for 35 questionnaires ( $n=10$ subjects).

Hence, the final sample consisted of 213 adolescents $(n=95$ females, 45\%) out of 181 families providing 572 questionnaires (Fig. 1).

\section{Chronotype and social jetlag}

The MCTQ includes questions regarding sleep and wake times during the week and weekend. The individual chronotype (continuously in h:min) was calculated as the Midpoint of Sleep (MSF), i.e., the half-way point between sleep-onset and sleep-end on free days [12] corrected for "oversleep" on free days (MSFsc) to account for sleep debt accumulated over the week [1]. The absolute value for social jetlag (SJL, continuously in h:min) was calculated as the difference between midpoint of sleep during free- and schooldays [7].

\section{Anthropometric measures}

Adolescents were measured annually by trained nurses according to standard procedures, dressed in underwear and barefoot. Standing height is measured to the nearest $0.1 \mathrm{~cm}$ using a digital stadiometer. Weight was measured to the nearest $0.1 \mathrm{~kg}$ with an electronic scale (model $753 \mathrm{E}$; Seca, Hamburg, German). Skinfold thickness was measured on the right side of the body at the biceps, triceps, subscapular, and suprailiac sites to the nearest $0.1 \mathrm{~mm}$ with a Holtain caliper (Holtain Ltd., Crymych, UK) [13]. Sexand age-independent body mass index $\left(\mathrm{BMI} \mathrm{kg} / \mathrm{m}^{2}\right)$ standard deviation scores (SDS) were calculated using the German national reference data according to the LMS Method [15]. Percent body fat (\%BF) was estimated from two skinfolds (triceps, subscapular) using age specific Slaughter equations [16], for the subsequent calculation of FMI (fat mass $/ \mathrm{m}^{2}$; where fat mass $=$ body weight $* \mathrm{BF} \% / 100$ ) and FFMI (fat free mass $/ \mathrm{m}^{2}$; where fat free mass = body weight - fat mass). Since the distribution of FMI was skewed, $\log 10$-transformed values were used in the analyses.

\section{Assessment of covariates}

Parents are interviewed regarding family characteristics (i.e., parental education, persons per household). Every 4 years maternal body weight and height were measured with the same equipment as for the children on the child's admission to the study center.

Adolescents' pubertal status was assessed in different ways: Tanner stage (breast and penis development) [17] was visually assessed by the study physician at each visit after the age of 5 years. After Tanner stage 2, boys self-assed Tanner stage in case they considered the visual inspection as intrusive. In addition, age at take-off (ATO), Age at Peak Height Velocity (APHV), i.e., the age at minimal (ATO) and maximal (APHV) height velocity (zero acceleration) representing the onset and end of puberty growth spurt.

\begin{tabular}{|c|c|c|}
\hline \multicolumn{3}{|c|}{ DONALD study participants July 2019 n=1.741 } \\
\hline \multicolumn{3}{|c|}{$2014^{1}-2019 \mathrm{n}=620$ participants with MCTQ Data ( $N=1.163$ Questionnaires) } \\
\hline & Exclusions: & \\
\hline & Two weeks after seasonal time change & $\mathrm{N}=89$ \\
\hline & Participants aged $>18$ years $^{2}$ & $N=378$ \\
\hline & Incomplete information on the MCTQ & $\mathrm{N}=3$ \\
\hline & Missing anthropometric data & $\mathrm{N}=35$ \\
\hline$\downarrow$ & Questionnaires excluded Total & $N=505$ \\
\hline
\end{tabular}

Remaining cohort after exclusions: $\mathrm{n}=299$ participants ( $\mathrm{N}=658$ Questionnaires)

Exclusion of those participants providing one single

Questionnaire only $\quad \mathrm{N}=86^{3}$

Final cohort for analyses: $n=213$ participants ( $N=572$ Questionnaires)

Fig. 1 Study Flow Diagram for participant data from the DONALD Study. ${ }^{1}$ Munich Chronotype Questionnaire Assessments (MCTQ) started in the DONALD Study. ${ }^{2}$ Participants above the age of 18 years were considered as being adult. ${ }^{3}$ Necessary exclusion criteria for the overall analyses, evident after the assessment of model assumptions. 
ATO and APHV were derived from the parametric Preece and Baines Model 1 (Preece and Baines, 1978), details are explained elsewhere [18, 19].

Individual total energy intake was calculated from weighed dietary records as individual means of three record days [14], collected in the weeks after anthropometric measurement. Physical activity was assessed [13] by an interview based questionnaire at the study center asking about the participation in organized and non-organized sports. Energy expenditure was estimated by multiplying the mean duration of activity (hours/ day) with the estimated basal metabolic rate (using age and sex depended algorithms according to Schofield [20], kcal/hour) and metabolic equivalents (MET, according to Ainsworth [21]. If information on covariates was not available for the same point in time at which MCTQ were administered and anthropometric measurements were taken, we considered covariate measurements taken within a 5-year time frame, while ensuring that these values were taken during adolescence (9-18 years).

\section{Statistical analyses}

All statistical analyses of the present evaluation were performed using $S A S^{\circ}$ procedures (version 9.4; Cary, NC, USA). The significance level was set at $p<$ 0.05 . The computer codes used for the analyses of the data during the current study are available from the corresponding author on reasonable request.

Linear mixed effects regression models (PROC MIXED in SAS), including both fixed and random effects, were used to analyze the association between change in MSFsc or SJL ( $\Delta$ MSFsc, $\Delta$ SJL, both in h:min, subtracting baseline exposure from exposure at each year of assessment with 0 difference at first assessment) and concurrent change of $\triangle B M I-S D S$, $\Delta \mathrm{FFMI}$ or $\Delta$ log-FMI during adolescence (Change-on-Change-Models) $[22,23]$. Mixed-effects regression models consider all available measurements per individual. Meaning the number of questionnaires per individual is allowed to differ [24].

Model building was driven by the log-likelihood criterion to define the final crude model. Covariates for model adjustment were selected according to known predictors of BMl, body composition, and chronotype or SJL $[25,26,8]$. From here, we drew a directed acyclic graph (DAG, Appendix Fig. 1) to identify minimally sufficient adjustment sets (msas) using a diagram representing the relationships among the identified variables [27], revealing age at baseline, time between first and subsequent measurements (basic model, details can be found elsewhere [23]), sex, ATO, number of persons in the household and maternal BMI $\left(\mathrm{kg} / \mathrm{m}^{2}\right)$ as important covariates. The joint inclusion of the msas represented the final model. To address potential biological differences by age arising from pubertal [27], chronobiological [3,9] or behavioral [28] driven changes in the association between $\Delta$ MSFsc or $\Delta \mathrm{SJL}$ and $\Delta$ body composition, we additionally stratified our data by age groups classified as: $<12$ years, $\geq 12$ to $\leq 15$ years and $>15$ years. The chosen cut-offs were identified in previous research $[4,5]$ as turning points in circadian changes. For the overall analyses we considered data from any single participant with at least two measurements to calculate the change from the first measurement taken per individual. This does not hold for the age group specific analyses. Age group $<12$ contains included 34 single measurements (18\%) and age group $\geq 12$ to $\leq 15$ years included seven single measurements (10\%). However, according to Jacobs et al. the change-on-change analyses is capable to capture this misbalance in the data [22]. Due to the open cohort design participants can occur in multiple age strata.

The Akaike Information Criterion and the Bayesian Information were used to select the correlation structure best describing the correlated nature of the data. Tests for effect modification were performed by the inclusion of interaction terms between chronotype or $\mathrm{SJ}$, age (years) and sex (boys/girls).

To manage missing data we undertook multiple imputations, using the MI procedure in SAS and explored the pattern of missingness. A comparison of differences in baseline characteristics between those with complete and incomplete data has been performed (Appendix Table 1). We generated an imputed database containing five imputed versions to predict missing values for ATO $(n=58,10 \%)$ and maternal BMI $(n=5$, $<1 \%$ ). Regression results were combined using the MIANALYZE procedure in SAS. Final models were tested regarding multicollinearity, heteroscedasticity, and normal distribution of residuals.

We performed the following sensitivity analyses: inclusion of total energy intake and physical activity, education of the mother, season of chronotype assessment as well as early life factors e.g., mothers' age at birth and weight gain during pregnancy. Furthermore, we excluded participants who used an alarm clock during the weekend $(n=59,10 \%)$. Besides stratification according to chronological age, we applied stratification by puberty stages (Tanner $<2$ and Tanner $\geq 2, p$ for interaction
$<0.05$ ) as suggested previously by Baird et al. [28]. Finally, we translated log FMI values in percent change for each one hour increase in the exposure variable ((exp(beta) -1$) * 100$ [29]) and calculated the populations absolute change in FMI based on the population median FMI at baseline.

\section{RESULTS}

During a median follow-up of 2.1 years (Q1-Q3:1.9-3.3 years) adolescents aged 9-18 years completed 3 MCTQs (Q1-Q3: 2-3). Table 1 shows the sample characteristics at first and last assessment during 2014 and 2019. On the population level BMISDS increased by $600 \%$ (from a negative to a positive SDS) and FMI by $11 \%$ in comparison to the first measurement taken. Both the MSFsc and SJL increased over time by almost 39 min and $17 \mathrm{~min}$, respectively, while sleep duration decreased by $45 \mathrm{~min}$ across the week. Family characteristics showed a high percentage of well-educated mothers with a normal body weight and a low percentage of smokers in the household.

After adjustment, greater $\triangle$ MSFsc was associated with a $5 \%$ increase in FMI $\mathrm{kg} / \mathrm{m}^{2}$ over time $(\beta=0.05(0.01,0.08), p=0.01)$. Considering the median FMI at baseline as the reference, this estimate would translate into a $0.2 \mathrm{~kg} / \mathrm{m}^{2}$ increase in FMl due to increasing lateness in chronotype during adolescence. Change in SJL was associated with BMI-SDS as well as log FMI. Associations for BMI-SDS and FMI were rather robust concerning confounder inclusion (Table 2) but not for FFMI. Stratified analysis by chronological age ( $p$ for interaction $<0.001$ ) revealed that the overall association reported for the complete sample including all adolescents aged 9-18 years is confined to the age group of 12-15-year-old adolescents (Table 3 ). No significant associations were seen in any of the other age groups. Of note, changes in MSFsc, SJL as well as changes in BMI-SDS, FFMI and FMI were greatest for the age group $\geq 12$ to $\leq 15$ years in comparison to the other age groups (Appendix Figs. 2 and 3). Stratified analyses according to Tanner stages (dichotomous with the cut-off at Tanner $\geq 2$ ) showed an association during puberty only (data not shown). There was no indication for significant interaction of the examined associations with sex (Appendix Table 1).

\section{DISCUSSION}

Our analyses confirm the association between MSFsc or SJL and body weight status and fat mass as observed in other studies. In addition, we could show the strongest associations between $\Delta$ MSFsc or $\Delta$ SJL and changes in overweight measures like $\Delta \mathrm{BMI}-$ SDS and $\triangle \mathrm{FMI}$ in the subgroup of adolescents aged $12-15$ years. This specific age group appears to be a vulnerable life stage for body composition changes due to a shift toward a later chronotype or greater SJL, during adolescence.

Despite different study designs and applied methodologies, most previous studies reported an association between chronotype or SJL and body composition $[5,7,8,29,30]$ with only few exceptions [31-33]. The evidence on chronobiology in relation to body composition is largest in adolescents but is mainly based on cross-sectional data.

To the best of our knowledge there is currently no comparable study that assessed change-on-change associations. However, among the longitudinal studies, Culnan et al. [34], investigated chronotype as a predictor of increased BMI in a group of 137 college freshman aged $18.3 \pm 0.6$ years over a period of 8 weeks. Participants having a late chronotype (based on the MorningnessEveningness Questionnaire) had a significantly greater BMI gain in comparison to participants with an early or medium chronotype (unstandardized beta $=0.50 \mathrm{BMI}$ points, $95 \%$ confidence interval $[\mathrm{Cl}]:[0.04,0.95], p=0,034)$. Another study analyzed the relevance of long term exposure to later bedtimes, which may reflect a later chronotype, from adolescence to adulthood in 3342 participants (age 12-32 years) for changes in BMI [35]. In that study, later 
Table 1. Characteristics ${ }^{\mathrm{a}}$ of $n=213$ adolescents (age 9-18 years, $N=$ 572 questionnaires) at first and last measurement over a maximum of 5 years follow-up, DONALD Study, 2015-2019 ${ }^{\text {. }}$

\begin{tabular}{|c|c|c|}
\hline Variable & First measurement & Last measurement \\
\hline Female $\mathrm{n}(\%)$ & $95(45)$ & \\
\hline Follow-up (years) ${ }^{c}$ & $2.1(1.9-3.3)$ & \\
\hline Age (years) & $12.9(11.0,15.0)$ & $15.1(14.6,18.0)$ \\
\hline \multicolumn{3}{|l|}{ Pubertal markers } \\
\hline \multicolumn{3}{|l|}{ Growth curves } \\
\hline Age at take-off (years) & $9.7(8.1,10.6)$ & \\
\hline o & $10.5(9.8,11.2)$ & \\
\hline q & $8.0(7.4,8.7)$ & \\
\hline $\begin{array}{l}\text { Age at peak height velocity } \\
\text { (years) }\end{array}$ & $12.8(11.3,14.0)$ & \\
\hline o & $13.6(12.9,14.6)$ & \\
\hline 운 & $11.2(10.5,11.9)$ & \\
\hline \multicolumn{3}{|l|}{ Anthropometric data } \\
\hline $\operatorname{BMI}\left(\mathrm{kg} / \mathrm{m}^{2}\right)$ & $19(17,22)$ & $20(18,23)$ \\
\hline BMI-SDS $\left(\mathrm{kg} / \mathrm{m}^{2}\right)$ & $-0.01(-0.69,0.76)$ & $0.05(-0.70,0.80)$ \\
\hline $\mathrm{FMI}\left(\mathrm{kg} / \mathrm{m}^{2}\right)$ & $4(2,5)$ & $4(3,6)$ \\
\hline FFMI $\left(\mathrm{kg} / \mathrm{m}^{2}\right)$ & $15(14,16)$ & $16(15,17)$ \\
\hline Overweight (yes) $^{d}$ & $33(15)$ & $28(13)$ \\
\hline \multicolumn{3}{|l|}{ Chronobiological variables (hh:mm) } \\
\hline MSFsC & $3: 28(3: 02,4: 15)$ & $4: 07(3: 23,5: 00)$ \\
\hline Social Jetlag & $1: 45(1: 15,2: 25)$ & $2: 02(1: 28,2: 45)$ \\
\hline Sleep onset week & $21: 55(21: 12,22: 40)$ & $22: 28(21: 30,23: 10)$ \\
\hline Sleep onset weekend & $00: 22(0: 01,0: 23)$ & $00: 04(0: 01,00: 23)$ \\
\hline Total sleep duration week & $08: 25(7: 35,9: 10)$ & $07: 40(7: 00,8: 30)$ \\
\hline Total sleep duration weekend & 09:45 (8:50, 10:30) & 09:00 (8:25, 09:55) \\
\hline $\begin{array}{l}\text { Wake up alone during } \\
\text { weekend }\end{array}$ & $182(85)$ & $186(87)$ \\
\hline \multicolumn{3}{|l|}{ Season of chronotype assessment } \\
\hline Spring & $46(21)$ & $44(21)$ \\
\hline Summer & $61(28)$ & $69(32)$ \\
\hline Autumn & $56(25)$ & $49(23)$ \\
\hline Winter & $50(25)$ & $51(24)$ \\
\hline \multicolumn{3}{|l|}{ Other risk factors } \\
\hline Total Energy Intake (kcal/d) & $1829(1558,2130)$ & $1831(1558,2210)$ \\
\hline Physical activity (kcal/d) & $328(198,562)$ & $361(207,543)$ \\
\hline \multicolumn{3}{|l|}{ Family characteristics } \\
\hline Persons per household & $4(3,4)$ & \\
\hline Overweight mothers ${ }^{f}$ & $66(31)$ & \\
\hline Highly educated mothers ${ }^{9}$ & $160(77)$ & \\
\hline $\begin{array}{l}\text { Smoking in the household } \\
\text { (yes) }\end{array}$ & $28(13)$ & \\
\hline
\end{tabular}

BMI Body mass index, SDS Standard Deviation Score, FMI Fat Mass Index, FFMI Fat Free Mass Index.

${ }^{a}$ Characteristics are presented prior imputation. The following variables had (n) missing values ATO (58), Tanner (127), Energy (72), physical activity (128), persons per household (121), maternal BMI (5), maternal education (10).

${ }^{\mathrm{b}}$ Results are presented as number and (percentage), median (25th, $75 \mathrm{~h}$ percentile) or mean \pm Standard Deviation.

${ }^{c}$ Follow-up was calculated as time between last and first measurement

dOverweight definitions according to the International Task Force BMI cutoffs for children corresponding to an adult BMI of $25 \mathrm{~kg} / \mathrm{m}^{2}$.

expressed as energy expenditure in kcal based on the sum of organized and unorganized sport activities.

$\mathrm{f} \geq 25 \mathrm{~kg} / \mathrm{m}^{2}$

$g_{\geq 12}$ years of schooling.

average workday bedtime by $1 \mathrm{~h}$ from adolescence to adulthood, was associated with an increase in BMI of $2.1 \mathrm{~kg} / \mathrm{m}^{2}$ per 6 years. Regarding SJL, Zwart et al. [33] found no association with BMI over 1 year in 83 adolescents aged 16 years and older. Still, their result could be interpreted as being in line with our analysis, as in their sample the critical time window for a meaningful exposure [5] may have passed and adolescents from age 16 years onwards may already have experienced transition toward an earlier chronotype again, resulting in lower $S J L$, which we did also highlight in our supplementary material (Appendix Fig. 2). Differences to our study were the use of BMI instead of age and sex adjusted BMI values (e.g., $z$-scores), the length in follow-up, study population, sample size and differences in confounder adjustments (i.e., Zwart et al. did not adjust for confounding variables) and the use of a single question regarding bedtime instead of a validated questionnaire assessing chronotype and SJL.

Based on Roenneberg et al. [1] we would consider a person with a MSFsc from 5:00 am onwards as being late. A large proportion $(>75 \%)$ of our adolescents is far away from that MSFsc and below the level of lateness found in other studies [25, 34], which may result in weaker associations with BMI-SDS in comparison to the associations found for SJL and BMI-SDS. SJL was already rather common at baseline in our study i.e., from the start of adolescence which has also been reported in previous studies [29, 36].

Many mechanisms are potentially involved in the associations between chronotype and body composition change (e.g., variable instead of constant sleep behavior during school and free days [37], shorter sleep [29], misalignment between the metabolic pathways and hormones [38], in particular ghrelin [39] and leptin [40], metabolic changes $[7,41]$ pro inflammatory state and cortisol [42] in combination with stress [43]). Carskadon et al. [44] even suggested pubertal changes e.g., due to the sensitivity of circadian rhythms to reproductive hormones [30], being responsible for the change in chronotype during adolescence. Puberty, as a period of greatest risk for body compositional changes induced by changes in chronotype, appears reasonable as most of the underlying mechanisms mentioned above, occur during the transition from childhood to adulthood [10,30]. Also, dietary changes during the transition toward lateness may be involved in the association with body composition changes, especially starting at age 12 years. As shown previously in the DONALD study, a greater eveningness in caloric intake during adolescence showed a higher overall caloric intake from age 11/12 years onwards but not earlier [45]. Changes in FFMI due to changes towards a later chronotype were no longer discernable after confounder adjustment, presumably because most importantly age and sex related changes in muscle mass explain the crude associations seen with chronotype. By contrast the association with BMI-SDS and FMI increases were not explained by covariates.

A major strength of this study is the prospective, longitudinal design of the DONALD study with repeated measurements collected on the same individual. This rich data allowed the determination of change over time and unmasking the dynamic nature of MSFsc, SJL and body composition during adolescence. Further strengths of this study relate to the use of the MCTQ as a validated method [1] applicable to adolescents [6] and the objective anthropometric measurements by trained staff at the DONALD study center, the assessment of many high qualitative covariates including Tanner staging [30], as well as other puberty measures (ATO, APHV) that allowed several sensitivity analyses.

FMI and FFMI calculations are based on measured body weight and estimated body fat percentage derived from skinfold thickness. Even though body fat estimates, based on the slaughter equation, are fairly valid in non-obese (non-overweight DONALD adolescents about $87 \%$ ) children [46], measurement error may still be a concern in terms of underestimating the true underlying association. However, the personal involved in the present study is trained regularly and thus, intra-observer variability and interobserver variability are notably reduced [13]. Despite the possible limitations for FMI and FFMI, the use of FMI next to BMI-SDS allows for a better interpretation [47] and validation [48] of our results, that showed a selective increase in fat mass. Also, confounding by 
Table 2. Regression coefficients of the linear mixed effects regression models for the association between change ( $\Delta$ ) in MSFsc or SJL and $\Delta$ BMI-SDS and $\Delta$ Body composition measures in $n=213$ participants ( $N=572$ questionnaires) of, DONALD Study, 2015-2019.

\begin{tabular}{|c|c|c|c|c|c|c|}
\hline \multirow[b]{2}{*}{ Outcome of interest } & \multicolumn{3}{|c|}{$\Delta$ MSFsc $^{\mathrm{a}}$} & \multicolumn{3}{|c|}{$\Delta \mathrm{SJL}^{\mathrm{b}}$} \\
\hline & beta & $95 \% \mathrm{Cl}$ & $p$ value & beta & $95 \% \mathrm{Cl}$ & $p$ value \\
\hline \multicolumn{7}{|l|}{$\Delta$ BMI-SDS } \\
\hline Model 1 & 0.06 & $(-0.01,0.14)$ & 0,11 & 0.08 & $(0.01,0.14)$ & 0.02 \\
\hline \multicolumn{7}{|l|}{$\Delta$ FFMI } \\
\hline Crude & 0.18 & $(0.04,0.32)$ & 0.02 & 0.29 & $(0.15,0.43)$ & $<0.0001$ \\
\hline \multicolumn{7}{|l|}{$\Delta \log \mathrm{FMl}$} \\
\hline Crude & 0.05 & $(0.01,0.08)$ & 0.01 & 0.06 & $(0.02,0.10)$ & 0.002 \\
\hline Model 1 & 0.05 & $(0.01,0.08)$ & 0.01 & 0.04 & $(0.003,0.08)$ & 0.03 \\
\hline
\end{tabular}

Crude: unadjusted model.

Model: 1 adjusted for age at baseline, sex, time between last and first measurement, age at take-off, persons in the household, maternal BMI (kg/m2). MSFsc Midpoint of sleep, SJL Social Jetlag, Cl Confidence Interval, BMI-SDS Body Mass Index-Standard Deviation Score $\left(\mathrm{kg} / \mathrm{m}^{2}\right)$, FFMI Fat Free Mass Index $\left(\mathrm{kg} / \mathrm{m}^{2}\right)$, FMI Fat Mass Index $\left(\mathrm{kg} / \mathrm{m}^{2}\right)$.

${ }^{\mathrm{a} B M I-S D S}$ models contain a random intercept and slope for chronotype change with a variance components structure (VC). FFMI models contain a random intercept and slope for chronotype change and time with a VC structure. Log FMI models contain a random intercept and slope for time with an unstructured covariance structure (UN).

${ }^{\mathrm{b}} \mathrm{BMI}-\mathrm{SDS}$ models contain a random intercept and slope for time with an un structure. FFMI models contain a random intercept and slope for time with a VC structure. Log FMI models contain a random intercept and slope for time with a VC structure.

Table 3. Results of the linear mixed effects regression models of the association between change $(\Delta)$ in MSFsc or SJL and $\Delta$ in BMI-SDS and $\Delta$ Body composition measures in $N=572(n=213)$ participants, stratified by age groups (years), DONALD Study, 2015-2019.

\begin{tabular}{|c|c|c|c|c|c|c|c|c|}
\hline & & & $\Delta$ MSFsc ${ }^{\mathrm{a}}$ & & & $\Delta \mathrm{SJL}^{\mathrm{b}}$ & & \\
\hline Outcome of interest ${ }^{c}$ & $\boldsymbol{N}$ & $n^{d}$ & beta & $95 \% \mathrm{Cl}$ & $p$ value & beta & $95 \% \mathrm{Cl}$ & $p$ value \\
\hline \multicolumn{9}{|l|}{$\Delta$ BMI-SDS change } \\
\hline Age $\geq 12 \leq 15$ & 196 & 67 & 0.14 & $(0.02,0.26)$ & 0.03 & 0.17 & $(0.07,0.30)$ & 0.003 \\
\hline Age $>15$ & 231 & 58 & 0.06 & $(-0.06,0.17)$ & 0.32 & 0.05 & $(-0.04,0.15)$ & 0.27 \\
\hline \multicolumn{9}{|l|}{$\Delta$ FFMI change } \\
\hline Age $\geq 12 \leq 15$ & 196 & 67 & 0.08 & $(-0.08,0.25)$ & 0.31 & 0.16 & $(-0.01,0.34)$ & 0.06 \\
\hline Age $>15$ & 231 & 58 & 0.04 & $(-0.16,0.24)$ & 0.70 & 0.02 & $(-0.19,0.24)$ & 0.84 \\
\hline \multicolumn{9}{|c|}{$\Delta$ Log transformed FMI change } \\
\hline Age $<12$ & 145 & 88 & 0.02 & $(-0.05,0.10)$ & 0.46 & -0.02 & $(-0.11,0.08)$ & 0.67 \\
\hline Age $\geq 12 \leq 15$ & 196 & 67 & 0.11 & $(0.05,0.16)$ & $<0.001$ & 0.12 & $(0.57,0.19)$ & 0.001 \\
\hline
\end{tabular}

MSFsC Midpoint of sleep, SJL Social Jetlag, Cl Confidence Interval, BMI-SDS Body Mass Index-Standard Deviation Score $\left(\mathrm{kg} / \mathrm{m}^{2}\right)$, FFMI Fat Free Mass Index $\left(\mathrm{kg} / \mathrm{m}^{2}\right)$, FMI Fat Mass Index $\left(\mathrm{kg} / \mathrm{m}^{2}\right)$.

aBMI-SDS models contain a random intercept and slope for chronotype change with a variance components structure (VC). FFMI models contain a random intercept and slope for chronotype change and time with a VC structure. Log FMI models contain a random intercept and slope for time with an unstructured covariance structure (UN).

${ }^{\mathrm{b}}$ BMI-SDS models contain a random intercept and slope for time with an un structure. FFMI models contain a random intercept and slope for time with a VC structure. Log FMI models contain a random intercept and slope for time with a VC structure.

${ }^{c}$ All models were adjusted for age at baseline, sex, time between last and first measurement, age at take-off, persons in the household, maternal BMI $\left(\mathrm{kg} / \mathrm{m}^{2}\right)$.

${ }^{\mathrm{d}} \mathrm{N}$ : total number of questionnaires, $\mathrm{n}$ : number of participants.

unknown or unmeasured covariates cannot be excluded. However, associations were rather stable regarding adjustment despite age and gender, which we considered in all adjusted models. Generalizability of our results may be limited since the DONALD study is characterized by a homogeneous sample of German participants, characterized by a high socioeconomic status. Even though, the prevalence overweight $(15,5 \%)$ is comparable to the overall German population (15, 4\%) [49].

Finally, the amount of missing covariables was low $(n=63$, $11 \%)$. Full case analyses would have likely biased our results differentially, meaning bias toward or away from the null. Therefore, multiple imputations were the best option to take care of missing data for the current analyses.

Our results contribute to the formulation of public health strategies regarding the risk reduction of overweight development during adolescence. Medical doctors should monitor adolescents carefully, especially from approximately age 12 years onwards, regarding changes in chronotype, since this change may contribute to circadian disruptions [41] leading to adverse effects on body composition $[1,26]$. Targeted advice regarding good 
sleep practices, for instance consistent sleep timing or reduction of blue light exposure e.g., screen time before bed, appears promising [50-52]. Monitoring of bedtimes by parents may influence the sleep timing and therefore decrease the level of SJL [53]. However, since chronotype preferences seem to be a naturally occurring phenomenon another strategy is to delay school starting times [54]. If school is not delayed it would be advisable to maintain early bedtime schedules across the week and during the weekend to reduce behavioral as well as metabolic changes [7]. Future studies should consider stratification by puberty status or at least age to unmask a potential dilution of the overall association due to the dynamic nature of this population in terms of biological and physiological changes. So far, the direction of the association between chronotype or SJL and fat mass remains to be studied [55]. Therefore, the next step requires the analyses of chronobiological changes during adolescence and the impact on adult body composition which would help to clarify on the temporal ambiguity.

To conclude, changes in chronotype and SJL were associated with changes in body composition particularly with body fat during adolescence and between 12 and 15 years of age. Improvements of the social environment to support adolescents in line with their late internal clock, would be helpful to reduce their risk for unfavorable changes in body composition in this critical life stage.

\section{REFERENCES}

1. Roenneberg $T$, Kuehnle $T$, Juda M, Kantermann $T$, Allebrandt $K$, Gordijn $M$, et al. Epidemiology of the human circadian clock. Sleep Med Rev. 2007;11:429-38. Available from http://www.sciencedirect.com/science/article/pii/S1087079207000895.

2. Wittmann M, Dinich J, Merrow M, Roenneberg T. Social Jetlag: Misalignment of Biological and Social Time. Chronobiol Int. 2006;23:497-509.

3. Roenneberg T, Merrow M. Entrainment of the human circadian clock. Cold Spring Harb Symp Quant Biol. 2007;72:293-9.

4. Randler $C$. Age and gender differences in morningness-eveningness during adolescence. J Genet Psychol. 2011;172:302-8.

5. Randler C, FaßI C, Kalb N. From Lark to Owl: developmental changes in morningness-eveningness from new-borns to early adulthood. Sci Rep. 2017;7:1-8. Available from https://www.nature.com/articles/srep45874.pdf.

6. Roenneberg T, Kuehnle T, Pramstaller PP, Ricken J, Havel M, Guth A, et al. A marker for the end of adolescence. Curr Biol. 2004;14:R1038-R1039. Available from http://www.sciencedirect.com/science/article/pii/S0960982204009285.

7. Roenneberg T, Allebrandt KV, Merrow M, Vetter C. Social Jetlag and Obesity. Curr Biol. 2012;22:939-43. Available from http://www.sciencedirect.com/science/ article/pii/S0960982212003259.

8. Malone SK, Zemel B, Compher C, Souders M, Chittams J, Thompson AL, et al. Social jet lag, chronotype and body mass index in 14-17-year-old adolescents. Chronobiol Int. 2016;33:1255-66. Available from https://www.ncbi.nlm.nih.gov/ pubmed/27715325.

9. Randler C, Haun J, Schaal S. Assessing the Influence of Sleep-Wake Variables on Body Mass Index (BMI) in Adolescents. 1 2013; 9:339-47. https://ejop.psychopen. eu/index.php/ejop/article/download/558/pdf.

10. Siervogel RM, Demerath EW, Schubert $C$, Remsberg KE, Chumlea WC, Sun $S$, et al. Puberty and Body Composition. Horm Res Paediatr. 2003;60:36-45. https://doi. org/10.1159/000071224.

11. Cheng G, Bolzenius K, Joslowski G, Günther ALB, Kroke A, Heinrich J, et al. Velocities of weight, height and fat mass gain during potentially critical periods of growth are decisive for adult body composition. Eur J Clin Nutr. 2015;69:262-8.

12. Roenneberg T, Wirz-Justice A, Merrow M. Life between Clocks: Daily Temporal Patterns of Human Chronotypes. J Biol Rhythms. 2003;18:80-90.

13. Kroke A, Manz F, Kersting M, Remer T, Sichert-Hellert W, Alexy U, et al. The DONALD Study. Eur J Nutr. 2004;43:45-54. https://doi.org/10.1007/s00394-004-0445-7.

14. Roßbach S, Diederichs T, Nöthlings U, Buyken AE, Alexy U. Relevance of chronotype for eating patterns in adolescents. Chronobiol Int. 2018;35:336-47.

15. Kromeyer-Hauschild K, Wabitsch M, Kunze D, Geller F, Geiß HC, Hesse V, et al. Perzentile für den Body-mass-Index für das Kindes- und Jugendalter unter Heranziehung verschiedener deutscher Stichproben. Monatsschrift Kinderheilkd. 2001;149:807-18. https://doi.org/10.1007/s001120170107.

16. Slaughter MH, Lohman TG, Boileau RA, Horswill CA, Stillman RJ.Van Loan MD,et al. Skinfold Equations for Estimation of Body Fatness in Children and Youth. Hum Biol. 1988;60:709-23. Available from https://www.jstor.org/stable/41464064.
17. Marshall WA, Tanner JM. Variations in pattern of pubertal changes in girls. Arch Dis Child. 1969;44:291-303. Available from https://pubmed.ncbi.nlm.nih.gov/5785179.

18. Buyken AE, Karaolis-Danckert N, Remer T. Association of prepubertal body composition in healthy girls and boys with the timing of early and late pubertal markers. Am J Clin Nutr. 2008;89:221-30.

19. Preece MA, Baines MJ. A new family of mathematical models describing the human growth curve. Ann Hum Biol. 1978;5:1-24.

20. Schofield WN. Predicting basal metabolic rate, new standards and review of previous work. Hum Nutr Clin Nutr. 1985;39:5-41.

21. Ainsworth BE, Haskell WL, Herrmann SD, Meckes N, Bassett DR, Tudor-Locke C, et al. 2011 Compendium of Physical Activities: a second update of codes and MET values. Med Sci sports Exerc. 2011;43:1575-81. Available from https://pubmed. ncbi.nlm.nih.gov/21681120/.

22. Jacobs DR Jr, Hannan PJ, Wallace D, Liu K, Williams OD, Lewis CE. Interpreting age, period and cohort effects in plasma lipids and serum insulin using repeated measures regression analysis: the CARDIA study. Statist. Med. 1999;18:655-79.

23. Libuda L, Alexy U, Buyken AE, Sichert-Hellert W, Stehle P, Kersting M. Consumption of sugar-sweetened beverages and its association with nutrient intakes and diet quality in German children and adolescents. Br J Nutr. 2009;101:1549-57. Available from https://www.cambridge.org/core/article/consumption-of-sugarsweetenedbeverages-and-its-association-with-nutrient-intakes-and-diet-quality-in-germanchildren-and-adolescents/8CB9DC5E70C4EFE13A44C21A7CF2A9E2.

24. Verbeke G, Molenberghs G. PROC MIXED versus PROC GLM. In: Linear mixed models for longitudinal data. Corr. 2. print. New York: Springer; 2001. (Springer series in statistics). p.119-120.

25. Arora T, Taheri S. Associations among late chronotype, body mass index and dietary behaviors in young adolescents. Int J Obes. 2015;39:39-44. https://doi. org/10.1038/ijo.2014.157.

26. Fischer D, Lombardi DA, Marucci-Wellman H.Roenneberg T, Chronotypes in the US - Influence of age and sex. PLoS ONE. 2017;12:e0178782. https://pubmed.ncbi. nlm.nih.gov/28636610.

27. Greenland S, Pearl J, Robins JM. Causal Diagrams for Epidemiologic Research. Epidemiology 1999; 10. https://journals.Iww.com/epidem/Fulltext/1999/01000/ Causal Diagrams for_Epidemiologic Research.8.aspx.

28. Baird J, Walker I, Smith C, Inskip H. Review of methods for determining pubertal status and age of onset of puberty in cohort and longitudinal studies. London, UK: CLOSER; 2017. https://www.closer.ac.uk/wp-content/uploads/CLOSERresource-Review-of-methods-fordetermining-pubertal-status-and-age-of-onsetof-puberty-in-cohort-and-longitudinal-studies.pdf. Accessed 20.10.2021.

29. Jarrin DC, McGrath JJ, Drake CL. Beyond Sleep Duration: Distinct Sleep Dimensions are Associated with Obesity in Children and Adolescent's. Int J Obes (Lond). 2013;37:552-8.

30. Hagenauer $\mathrm{MH}$, Lee TM. The Neuroendocrine Control of the Circadian System: adolescent chronotype. Front Neuroendocrinol. 2012;33:211-29.

31. Maukonen $M$, Kanerva $N$, Partonen $T$, Kronholm $E$, Konttinen $H$, Wennman $H$, et al. The associations between chronotype, a healthy diet and obesity. Chronobiol Int. 2016;33:972-81.

32. Baron KG, Reid KJ, Kern AS, Zee PC. Role of sleep timing in caloric intake and BMI. Obes (Silver Spring). 2011;19:1374-81.

33. de Zwart BJ, Beulens JWJ, Elders P, Rutters F. Pilot data on the association between social jetlag and obesity-related characteristics in Dutch adolescents over one year. Sleep Med. 2018;47:32-5.

34. Culnan E, Kloss JD, Grandner M. A prospective study of weight gain associated with chronotype among college freshmen. Chronobiol Int. 2013;30:682-90.

35. Asarnow LD, McGlinchey E, Harvey AG. Evidence for a Possible Link between Bedtime and Change in Body Mass Index. Sleep. 2015;38:1523-7.

36. Stoner L, Castro N, Signal L, Skidmore P, Faulkner J, Lark S, et al. Sleep and Adiposity in Preadolescent Children: the Importance of Social Jetlag. Child Obes. 2018;14:158-64.

37. Zeron-Rugerio MF, Cambras T, Izquierdo-Pulido M. Social Jet Lag Associates Negatively with the Adherence to the Mediterranean Diet and Body Mass Index among Young Adults. Nutrients. 2019;11:1756. https://pubmed.ncbi.nlm.nih.gov/ 31366143/.

38. Garaulet M, Gómez-Abellán P, Alburquerque-Béjar JJ, Lee Y-C, Ordovás JM, Scheer FALL. Timing of food intake predicts weight loss effectiveness. Int J Obes (Lond). 2013;37:604-11. Available from https://www.ncbi.nlm.nih.gov/pubmed/23357955.

39. Qian J, Morris CJ, Caputo R, Garaulet M, Scheer, Frank AJL. Ghrelin is impacted by the endogenous circadian system and by circadian misalignment in humans. Int J Obes (Lond). 2019;43:1644-9. Available from https://www.ncbi.nlm.nih.gov/ pubmed/30232416.

40. Scheer FA, Morris CJ, Shea SA. The internal circadian clock increases hunger and appetite in the evening independent of food intake and other behaviors. Obes (Silver Spring). 2013;21:421-3. Available from https://www.ncbi.nlm.nih.gov/ pubmed/23456944. 
41. Gonnissen HKJ, Rutters F, Mazuy C, Martens EAP, Adam TC, Westerterp-Plantenga MS. Effect of a phase advance and phase delay of the 24-h cycle on energy metabolism, appetite, and related hormones. Am J Clin Nutr. 2012;96:689-97.

42. de Punder K, Heim C, Entringer S. Association between chronotype and body mass index: the role of C-reactive protein and the cortisol response to stress. Psychoneuroendocrinology. 2019;109:104388. Available from http://www. sciencedirect.com/science/article/pii/S0306453019301131.

43. Lucassen $E A$, Zhao $X$, Rother $\mathrm{Kl}$, Mattingly $M S$, Courville $A B$, de Jonge $L$, et al. Evening Chronotype Is Associated with Changes in Eating Behavior, More Sleep Apnea, and Increased Stress Hormones in Short Sleeping Obese Individuals. PLoS ONE. 2013;8:e56519. Available from https://pubmed.ncbi.nlm.nih.gov/23483886/.

44. Carskadon MA, Vieira C, Acebo C. Association between puberty and delayed phase preference. Sleep. 1993;16:258-62.

45. Diederichs T, Perrar I, Roßbach S, Alexy U, Buyken AE. In adolescence a higher 'eveningness in energy intake' is associated with higher total daily energy intake. Appetite. 2018;128:159-66. Available from http://www.sciencedirect.com/ science/article/pii/S0195666318301119.

46. Freedman DS, Horlick M, Berenson GS. A comparison of the Slaughter skinfoldthickness equations and BMI in predicting body fatness and cardiovascular disease risk factor levels in children. Am J Clin Nutr. 2013;98:1417-24.

47. Lu Y, Shu H, Zheng Y, Li C, Liu M, Chen Z, et al. Comparison of fat-free mass index and fat mass index in Chinese adults. Eur J Clin Nutr. 2012;66:1004-7. https://doi. org/10.1038/ejcn.2012.86.

48. Peltz G, Aguirre MT, Sanderson M, Fadden MK. The role of fat mass index in determining obesity. Am J Hum Biol. 2010;22:639-47. Available from https:// pubmed.ncbi.nlm.nih.gov/20737611.

49. Schienkiewitz A, Brettschneider A-K, Damerow S, Rosario AS. Übergewicht und Adipositas im Kindes- und Jugendalter in Deutschland - Querschnittergebnisse aus KiGGS Welle 2 und Trends: Robert Koch-Institut, Epidemiologie und Gesundheitsberichterstattung. JoHM. 2018;3:16-23. Available from: https://doi. org/10.17886/RKI-GBE-2018-005.2.

50. Lee S, Hale L, Chang A-M, Nahmod NG, Master L, Berger LM, et al. Longitudinal associations of childhood bedtime and sleep routines with adolescent body mass index. Sleep. 2019;42:zsy202. Available from https://pubmed.ncbi.nlm.nih.gov/ 30517720/.

51. Hayes JF, Balantekin KN, Altman M, Wilfley DE, Taylor CB, Williams J. Sleep Patterns and Quality Are Associated with Severity of Obesity and Weight-Related Behaviors in Adolescents with Overweight and Obesity. Child Obes. 2018;14:11-7.

52. Asarnow LD, Greer SM, Walker MP, Harvey AG. The Impact of Sleep Improvement on Food Choices in Adolescents With Late Bedtimes. J Adolesc Health. 2017;60:570-6.

53. Randler C, Bilger S. Associations among sleep, chronotype, parental monitoring, and pubertal development among German adolescents. J Psychol. 2009;143:509-20.

54. Minges KE, Redeker NS. Delayed school start times and adolescent sleep: a systematic review of the experimental evidence. Sleep Med Rev. 2016;28:86-95. https://doi.org/10.1016/j.smrv.2015.06.002.

55. Almoosawi S, Vingeliene S, Gachon F, Voortman T, Palla L, Johnston JD, et al. Chronotype: Implications for Epidemiologic Studies on Chrono-Nutrition and Cardiometabolic Health. Adv Nutr (Bethesda, Md). 2019;10:30-42. Available from https://pubmed.ncbi.nlm.nih.gov/30500869/.

\section{ACKNOWLEDGEMENTS}

The DONALD Study is financially supported by the Ministry of Science and Research of North Rhine Westphalia, Germany. This analysis was funded by the Deutsche Forschungsgemeinschaft (DFG, German Research Foundation)-AL 1794/1-2. The participation of all children and their families in the DONALD Study is gratefully acknowledged. We also thank the DONALD staff for carrying out the anthropometric measurements, for administering the questionnaires, and for collecting and coding the dietary records. We do thank Dr Johanna Conrad who read the final paper and gave us valuable feedback during the data analyses.

\section{AUTHOR CONTRIBUTIONS}

The authors alone are responsible for the content and writing of the paper. SSch, $A B$, $\mathrm{UA}$ and $\mathrm{NJ}$ conceived and designed the work that led to the submission. All authors (NJ, SSch, BK, UN, AB, UA) played an important role in interpreting the results. NJ was responsible for the data analyses and drafted the paper. All coauthors revised and approved the current paper. The corresponding author confirms that she has had full access to the data in the study and final responsibility for the decision to submit for publication.

\section{FUNDING}

Open Access funding enabled and organized by Projekt DEAL.

\section{COMPETING INTERESTS}

The DONALD Study is financially supported by the Ministry of Science and Research of North Rhine Westphalia, Germany. This analysis was funded by the Deutsche Forschungsgemeinschaft (DFG, German Research Foundation)-AL 1794/1-2. The authors report no competing interests. The authors alone are responsible for the content and writing of the paper. SS, AB, UA and NJ conceived and designed the work that led to the submission. All authors played an important role in interpreting the results. $\mathrm{NJ}$ drafted the paper and all coauthors revised and approved the current paper. The corresponding author confirms that she has had full access to the data in the study and final responsibility for the decision to submit for publication.

\section{ADDITIONAL INFORMATION}

Supplementary information The online version contains supplementary materia available at https://doi.org/10.1038/s41430-021-01024-y.

Correspondence and requests for materials should be addressed to Nicole Jankovic.

Reprints and permission information is available at http://www.nature.com/ reprints

Publisher's note Springer Nature remains neutral with regard to jurisdictional claims in published maps and institutional affiliations.

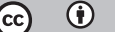

Open Access This article is licensed under a Creative Commons Attribution 4.0 International License, which permits use, sharing, adaptation, distribution and reproduction in any medium or format, as long as you give appropriate credit to the original author(s) and the source, provide a link to the Creative Commons license, and indicate if changes were made. The images or other third party material in this article are included in the article's Creative Commons license, unless indicated otherwise in a credit line to the material. If material is not included in the article's Creative Commons license and your intended use is not permitted by statutory regulation or exceeds the permitted use, you will need to obtain permission directly from the copyright holder. To view a copy of this license, visit http://creativecommons. org/licenses/by/4.0/.

(c) The Author(s) 2021 